A\&L

ISSN 2709-0205

Vol 2 Issue 2 (2021)

\title{
Effect of ATP and molsidomine combination on contractile function of isolated adult and old rat hearts during adequate coronary perfusion, at ischemia and reperfusion
}

\author{
Vladislav V. Bezrukov, Liana P. Kuprash, Nina V. Sykalo, Tetyana V. Panteleymonova, Ludmila B. \\ Sharabura, Vitaliy V. Olar
}

D. F. Chebotarev Institute of Gerontology NAMS of Ukraine, Kyiv, Ukraine

https://doi.org/10.47855/jal9020-2021-2-2

Correspondence: sykalo@geront.kiev.ua

Received: 17.05.2021; Accepted: 07.07.2021; Published: 07.07.2021

\begin{abstract}
Pathology of the cardiovascular system occupies a major place in the structure of diseases of the elderly and old patients. Metabolic disturbances are very important in ischemic damages of myocardium in the elderly and old people. So, drugi with metabolic mechanism of action is very ppromising in the treatment of elderly patients with cardiovascular diseases. The relevance of this study is determined by the feasibility of using drugs of metabolic action, which have a beneficial effect on the metabolism of cardiomyocytes, improve blood supply to the myocardium, increase its contractile function. The effect of ATP-molsidomine combination on myocardial contractility in different age animals was stuiesy in vitro experiments. The experiments on the isolated hearts from adult and old rats have shown that combined use of ATP and molsidomine did not significantly affect the contractility of the isolated hearts of adult rats under different perfusion regimes. In old rats, the use of ATP-molsidomine combination had a positive effect on the contractile function of the myocardium under the influence of damaging factors (ischemia, reperfusion): prevented a decrease of left ventricular developing pressure and its first derivative (velocity of pressure rise and velocity of pressure decline) and accelerated its growth during reperfusion. Coadministration of ATP and molsidomine during ischemia had a positive effect on the heart rhythm and restored heart rate at the reperfusion period in adult and old rats. The results of the study indicate a positive effect of the ATP-molsidomine combination on the myocardial contractility in old rats. Combined use of ATP and molsidomine exerted a favourable influence on the heart rhythm under damaging factors both in the adult and old animals.
\end{abstract}

Key words: ATP; molsidomine; isolated rat heart; myocardial contractility; ageing

Coronary heart disease (CHD) is one of the important causes of population `s disability and mortality in economic-developed countries to the time being. Many investigators emphasized the role of the myocardial cytoprotection in a coronary disease treatment, because metabolic disturbances are a very important cause of ischemic damages of myocardium in the elderly and old people. So, using drugs with metabolic mechanism of action is very perspective in treatment of elderly patients with cardiovascular diseases [1,2].

In many elderly people exacerbation of the coronary insufficiency is due to an increased blood pressure. The factors, provoking the development of decompensation among the elderly patients with $\mathrm{CHD}$, are bronchopulmonary diseases, physical and alimentary loads, psycho-emotional stress and the attacks of paroxysmal tachycardia.

In the treatment of elderly people with CHD, it is necessary to take into account the predominance of certain mechanisms of ischemic heart disease development. The main goal of the treatment of such patients is the minimization of the overall risk of the complications, death from these diseases and improvement of the prognosis. This provides not only an adequate treatment of the CHD but also 
correction of other modified risk factors, as well as treatment of the concomitant diseases (hypertension, diabetes, etc.). Therefore, in the treatment of CHD, in each particular case, it is necessary to take into account the concomitant diseases, age and metabolic changes.

To increase the effectiveness of treatment of CHD patients, it is advisable to include in their complex therapy drugs of coordination compounds based on adenosine triphosphate, in particular ATPlong, which has an antianginal effect and increases physical activity tolerance and heart efficiency, normalization of reduced inotropic reserve of myocardium and reverse development of diastolic dysfunction by the relaxation type [3,4].

The quality of ATP to influence on blood pressure and heart rhythm deserves attention. At the same time, even if the hypotensive effect of ATP monotherapy is not great, the achieved effect is quite stable [5]. The described quality of ATP is connected with a vasodilator influence of its purine nucleoside adenosine [6].

Sydnonimines may be used for the patients with heart failure. Molsidomine is an antianginal remedy in the group of sydnonimines. In the opinion of a number of researchers, molsidomine also has an arteriodilating effect. This leads to a decrease of the arterial blood pressure and the total vascular resistance along with an increase of stroke and cardiac indices with an increased level of congestion on the heart [1, 7].

Thus, ATP and molsidomine exhibit a similar effect on the hemodynamic parameters.

The purpose of this study is to establish the impact of a combined application of ATP and molsidomine on the myocardial function of the adult and old rats with an adequate coronary perfusion, ischemia and reperfusion.

\section{Materials and methods}

The effect of ATP-molsidomine combination on myocardial contractility was studied on isolated heart model [8]. The isolated heart represents a successful model for study of certain age-related changes in the heart contractile function, as it excludes the effects of the extracardiac factors.

The experiments were carried out on the isolated hearts from 21 male rats of two age groups: adult (7-8 months) and old (25-26 months). Coronary perfusion was performed according to Langendorff, using a solution of the following composition (mmol/l): $\mathrm{NaCl}-118 ; \mathrm{KCl}-4.7 ; \mathrm{MgSO}_{4}-1 ; \mathrm{NaH}_{2} \mathrm{PO}_{4}-1.2 ; \mathrm{NaHCO}_{3}$ $-25 ; \mathrm{CaCl}_{2}-2.5$; glucose -11 . The perfusate was aerated with carbogen $\left(\mathrm{O}_{2}: \mathrm{CO}_{2}=95: 5\right)$.

The solution temperature $37^{\circ} \mathrm{C}$ and $\mathrm{pH} 7.4$ were maintained at constant levels.

Using a latex ballon guided into the left ventricle, the maximally developing pressure (Pmax) and its first derivative $(\mathrm{dP} / \mathrm{dt})$ were measured [8]. The state of the left ventricle myocardial contractility was judged about from the Pmax parameters, $+\mathrm{dP} / \mathrm{dt}$ and $-\mathrm{dP} / \mathrm{dt}$. Electrograms were registered to analyze the heart contractions rhythm. The isolated heart was contracting in a spontaneous rhythm and isovolumic mode. The time period for its adaptation was 15-20 min.

The value of left ventricular pressure (Pmax) and its first derivative $(\mathrm{dP} / \mathrm{dt})$ was determined under conditions of adequate coronary perfusion, ischemia and reperfusion. ATP-long, $100 \mathrm{nmol} / \mathrm{l}$, and molsidomine, $100 \mathrm{nmol} / \mathrm{l}$, were added to the buffer solution during ischemia.

Statistical analyses of the obtained data were performed using Student`s t-test.

\section{Results and discussion}

\section{Effects of ATF and molsidomine on the contractile ability of an isolated heart of adult rats.}

Effects of the combined application of ATP (100 nmol / 1) and molsidomine (100 nmol / 1) on the power (maximum pressure developed by the left ventricle of the isolated heart - Pmax, $\mathrm{kPa}$ ) and speed (the velocity of pressure rise and decline in the left ventricle of the isolated heart - $+\mathrm{dP} / \mathrm{dt}$ and $-\mathrm{dP} / \mathrm{dt}$, respectively) indicative of the myocardial contractility have been investigated.

It appeared that all indicators of the myocardial contractility of adult rats (Pmax, $+\mathrm{dP} / \mathrm{dt},-\mathrm{dP} / \mathrm{dt}$ ) and heart rate (HR) were significantly decreased in the case of ischemia, but during reperfusion they were restored to the initial level (Fig. 1, 2, 3, 4).

In adult rats the pressure was maximally developed by the left ventricle of an isolated heart (Pmax, $\mathrm{kPa})$, being the same in the control and experimental animals (Fig. 1). 


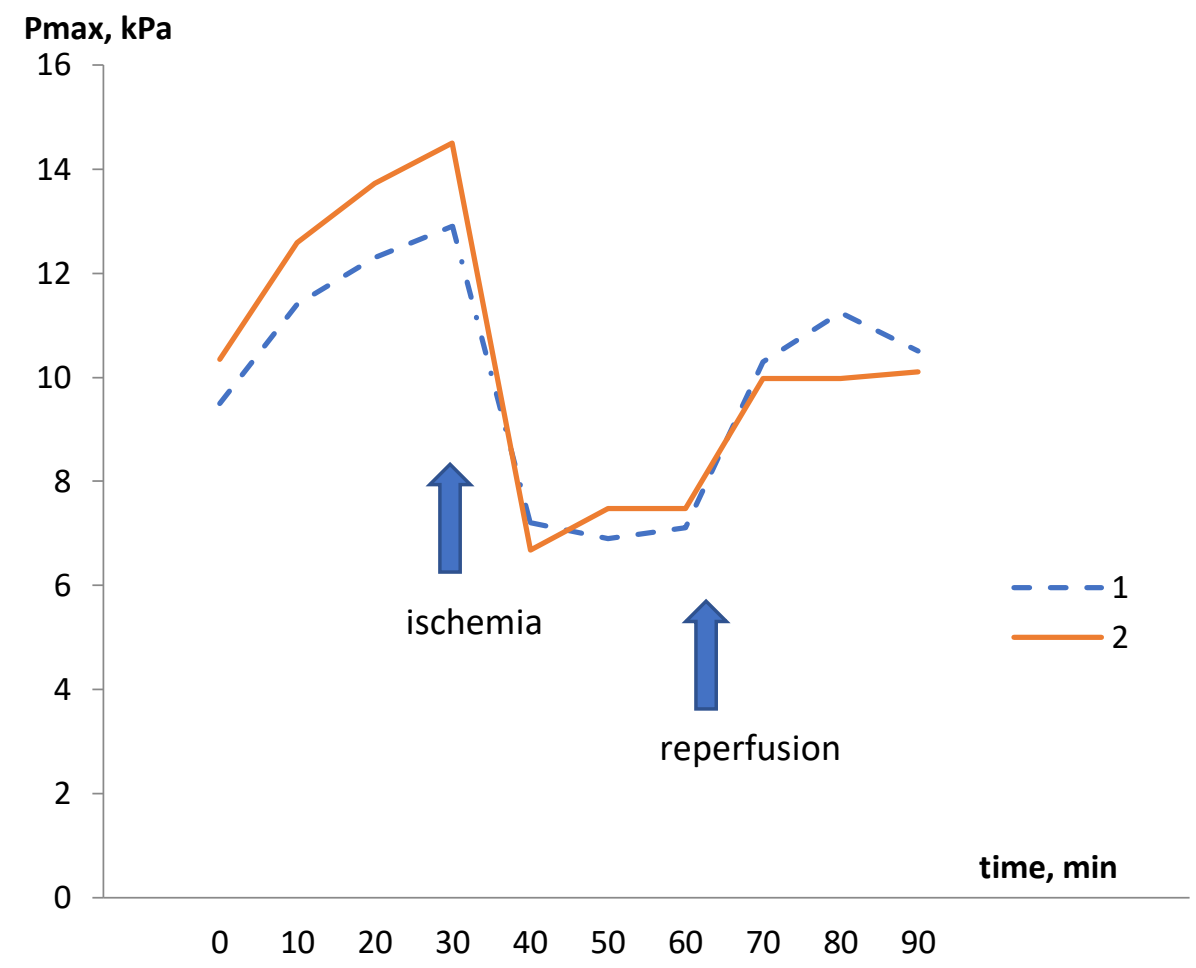

Figure 1. Effect of ATP-molsidomine combination on the maximum pressure developed by left ventricle (Pmax, $\mathrm{kPa}$ ) of isolated adult rat hearts under conditions of adequate coronary perfusion, ischemia and reperfusion.

Notes: 1 -control - intact animals; 2 - experiment - ATP + molsidomine.

Under different modes of perfusion (adequate coronary perfusion, ischemia, reperfusion), there were no significant differences in Pmax between control and experimental animals. In such a way, in adult rats, ATP and molsidomine do not affect the pressure (Pmax) maximally developed by the left ventricle of an isolated heart under the action of damaging factors - ischemia and reperfusion

The same regularities have been identified during the study of speed indicators of myocardial function - the velocity of pressure rise and decline in the left ventricle of an isolated heart of adult rats (+ $\mathrm{dP} / \mathrm{dt}$, $-\mathrm{dP} / \mathrm{dt}$, respectively). Thus, the dynamics of the velocity of pressure rise and decline in the left ventricle of an isolated heart of the adult rats does not significantly differs for control and experimental animals (Fig. 2, 3). 


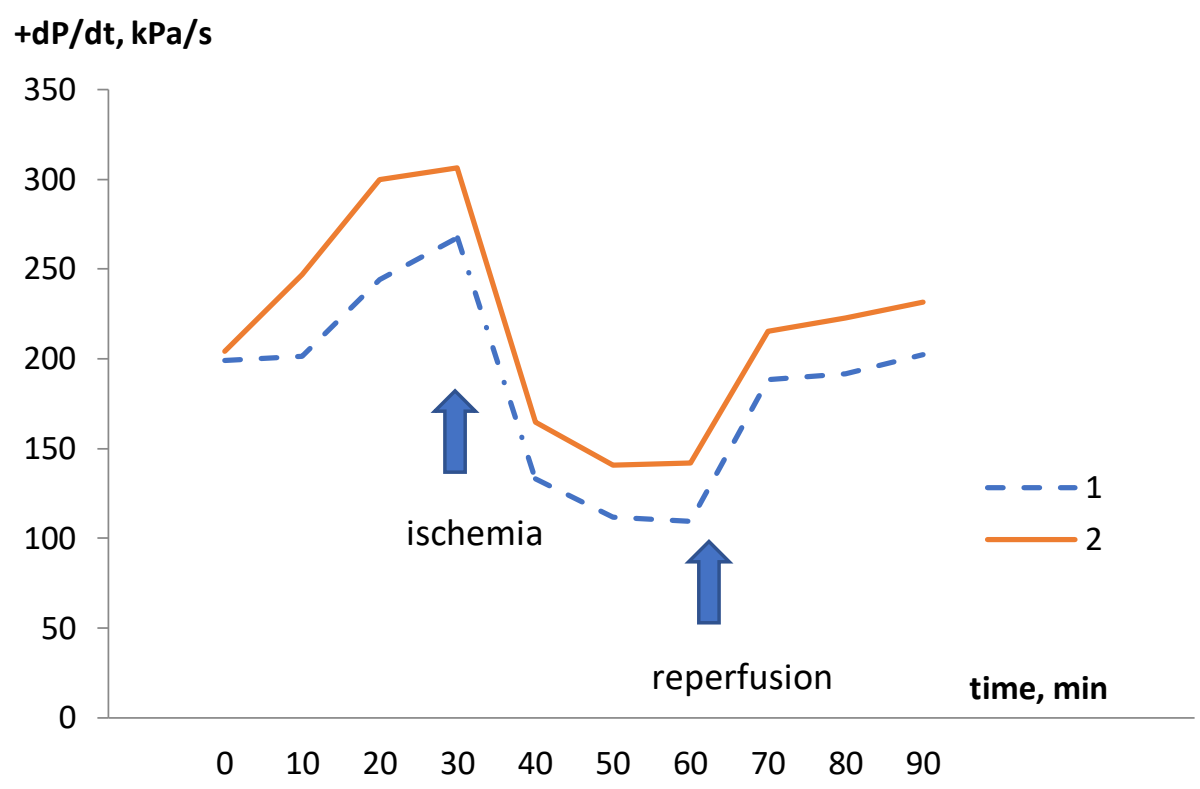

Figure 2. Effect of ATP-molsidomine combination on velocity of pressure rise in the left ventricle $(+\mathrm{dP} / \mathrm{dt}, \mathrm{kPa} / \mathrm{s})$ of isolated adult rat hearts under conditions of adequate coronary perfusion, ischemia and reperfusion.

Notes: 1 -control - intact animals; 2 - experiment - ATP + molsidomine.

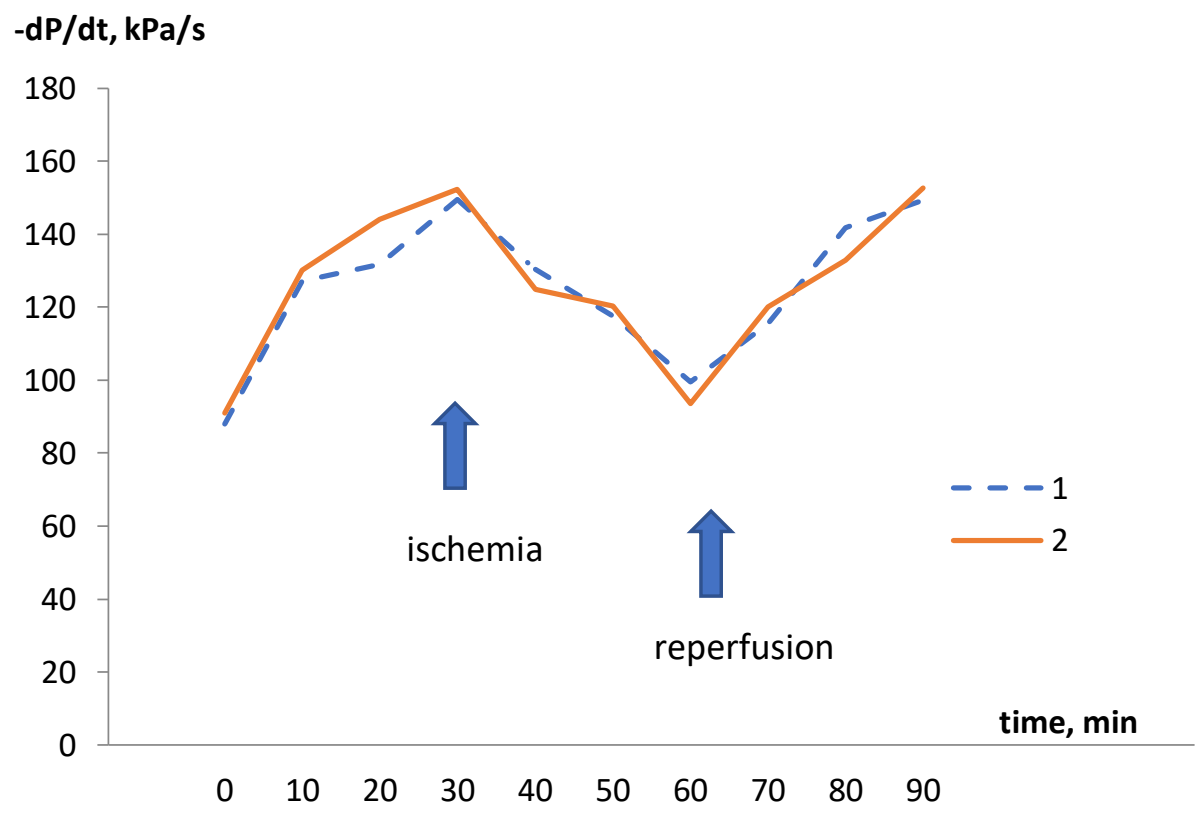

Figure 3. Effect of ATP-molsidomine combination on velocity of pressure decline in the left ventricle $(-\mathrm{dP} / \mathrm{dt}, \mathrm{kPa} / \mathrm{s})$ of isolated adult rat hearts under conditions of adequate coronary perfusion, ischemia and reperfusion.

Notes: 1 - control - intact animals; 2 - experiment - ATP + molsodomine. 
In such a way, in adult rats, the combined use of ATP and molsidomine does not significantly influence the contractile ability of an isolated heart under different perfusion modes.

At the same time, study of the heart rate in adult rats showed a positive effect of ATP and molsidomine on the heart rate. So, in control and experimental animals with ischemia, the heart rate decreases significantly (Fig. 4).

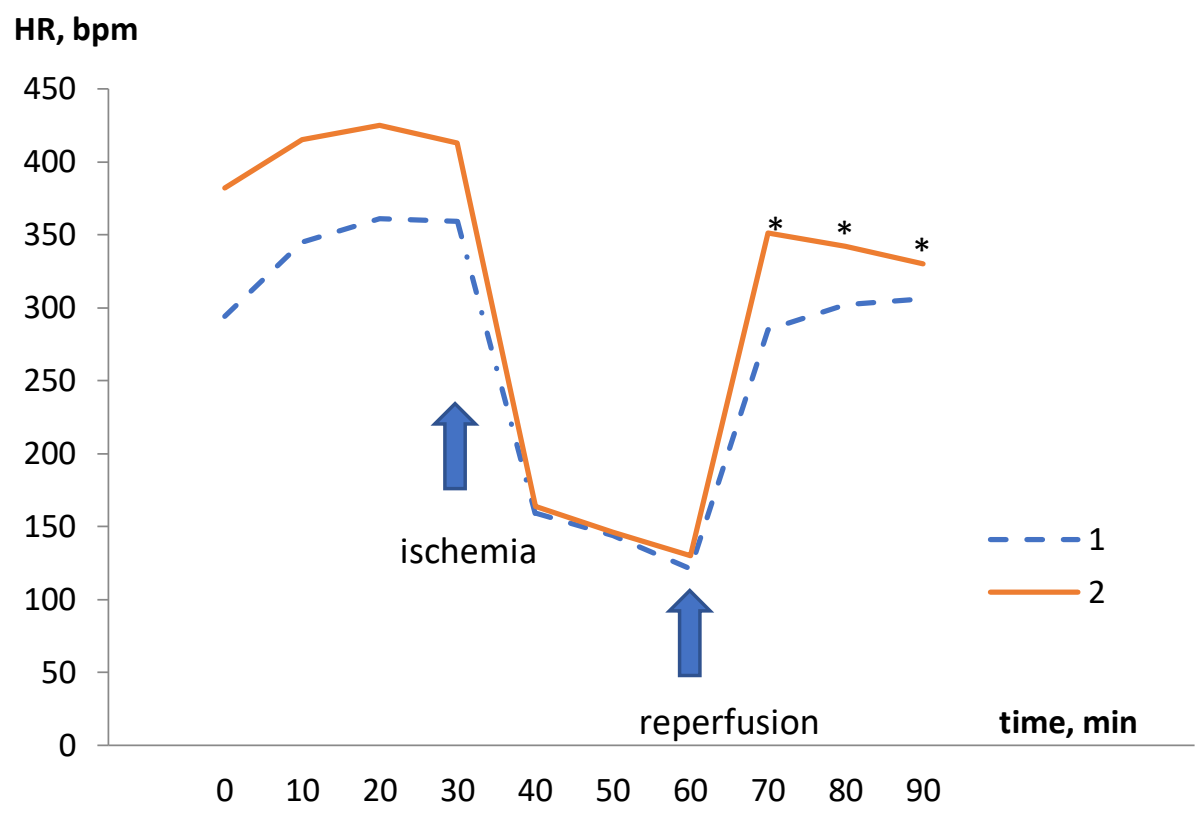

Figure 4. Effect of ATP-molsidomine combination on the heart rhythm (bpm) of isolated adult rat hearts under conditions of adequate coronary perfusion, ischemia and reperfusion .

Notes: 1 - control - intact animals; 2 - experiment - ATP + molsidomine.

* - P $<0.05$ - compared to control.

During reperfusion, the heart rate is updated almost to the initial values in both, the control and the experimental rats, but the value of this indicator is significantly higher for the experimental animals.

In such a way, the combined use of ATP and molsidomine contributes to the restoration of the heart rhythm in adult rats during reperfusion after ischemia.

Thus, the combined use of ATP and molsidomine does not significantly influences the contractile ability of an isolated heart of adult rats in different modes of perfusion, but has a positive effect on the restoration of the heart rate after ischemia during the period of reperfusion.

\section{Influence of ATP and molsidomine on the contractility of isolated hearts of old rats.}

In old rats, the combined effect of ATP $(100 \mathrm{nmol} / \mathrm{L})$ and molsidomine $(100 \mathrm{nmol} / \mathrm{L})$ on the function of an isolated heart showed significant differences in comparison with intact animals. Thus, the pressure maximally developed by the left ventricle of an isolated heart (Pmax) although being decreased during ischemia in both groups of animals, was significantly less manifested among the experimental rats in comparison with the control animals (Fig. 5). During the adequate coronary perfusion, as well as during the reperfusion period, the values of this indicator did not significantly differ for the control and experimental animals. 


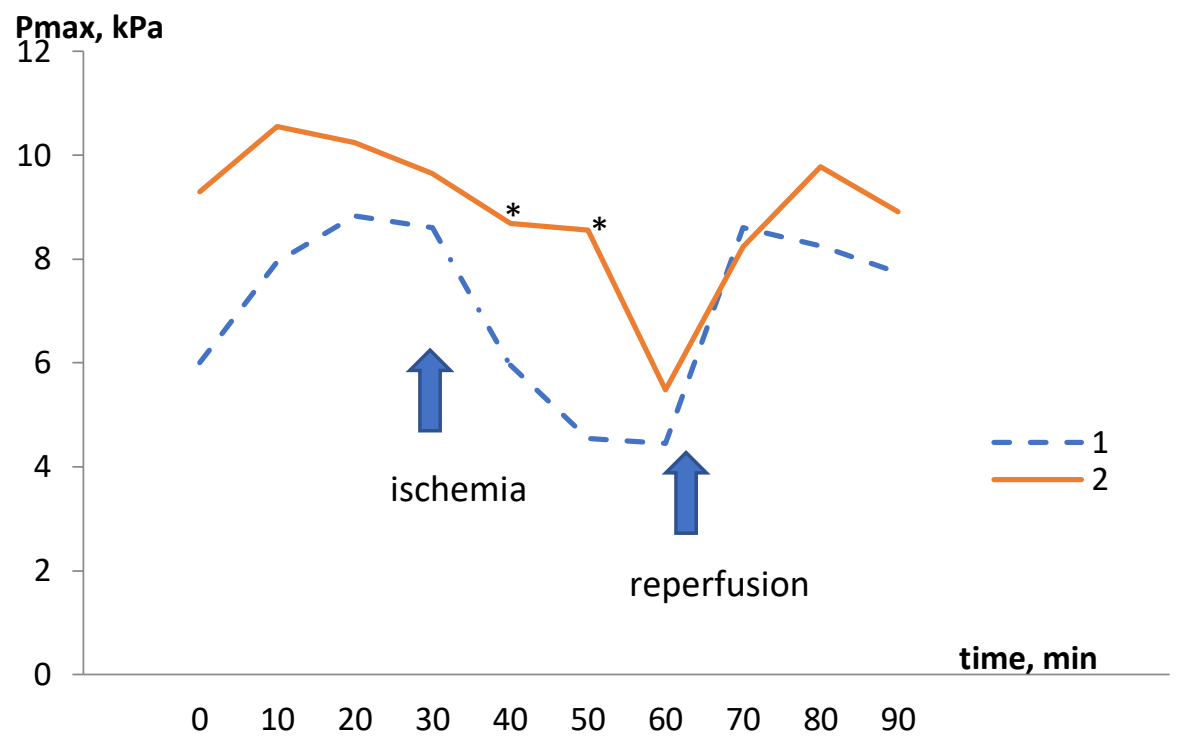

Figure 5. Effect of ATP-molsidomine combination on the maximum pressure developed by the left ventricle $(\mathrm{Pmax}, \mathrm{kPa})$ of isolated old rat hearts under conditions of adequate coronary perfusion, ischemia and reperfusion.

Notes: 1 - control - intact animals; 2 - experiment - ATP + molsidomine.

The velocity of pressure rise in the left ventricle of the isolated heart of old animals $(+\mathrm{dP} / \mathrm{dt}, \mathrm{kPa} / \mathrm{s})$ was somewhat lower for the control rats in comparison with the experimental ones with adequate coronary perfusion and ischemia, but significant differences between control and experimental animals were observed during the reperfusion (Fig. 6).

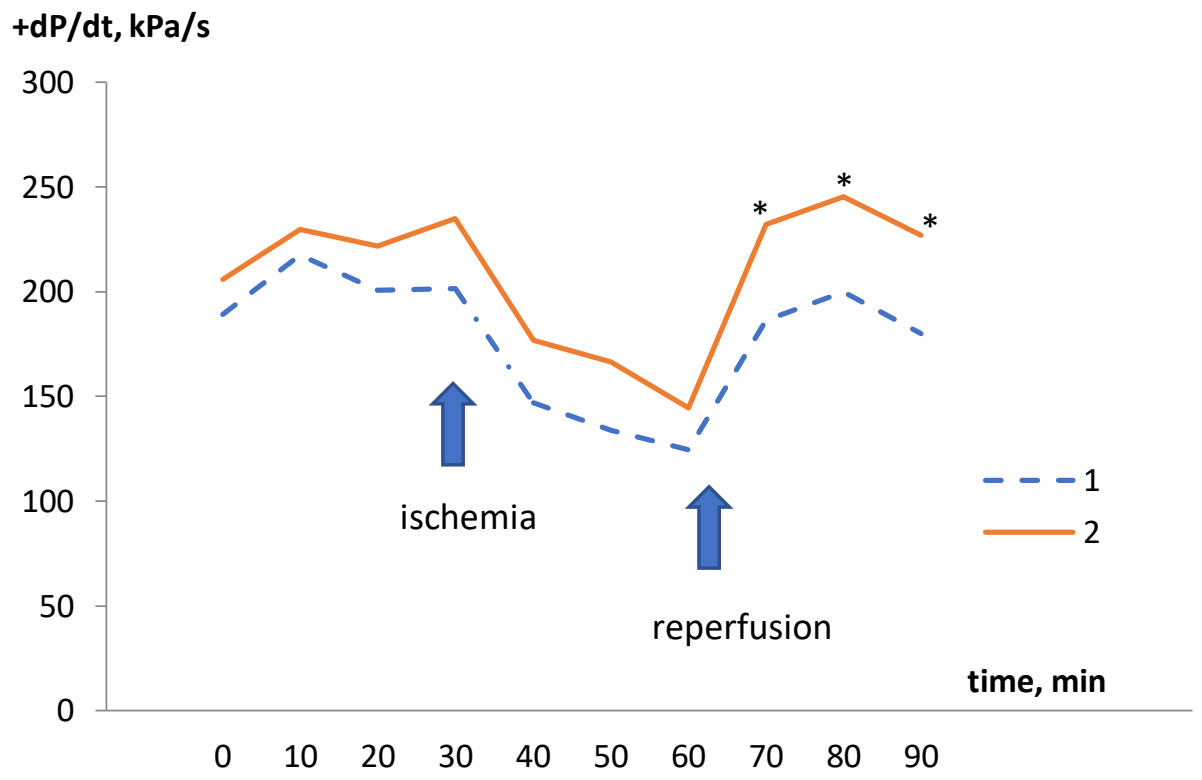

Figure 6. Effect of ATP-molsidomine combination on velocity of pressure rise in the left ventricle $(+\mathrm{dP} / \mathrm{dt}, \mathrm{kPa} / \mathrm{s})$ of isolated old rat hearts under conditions of adequate coronary perfusion, ischemia and reperfusion.

Notes: 1 - control - intact animals; 2 - experiment - ATP + molsidomine.

* $-\mathrm{P}<0.05$ - compared to control. 
The velocity of pressure decline in the left ventricle of an isolated heart $(-\mathrm{dP} / \mathrm{dt}, \mathrm{kPa} / \mathrm{s})$ of old rats was also significantly higher during the reperfusion period when using ATP and molsidomine (Fig. 7).

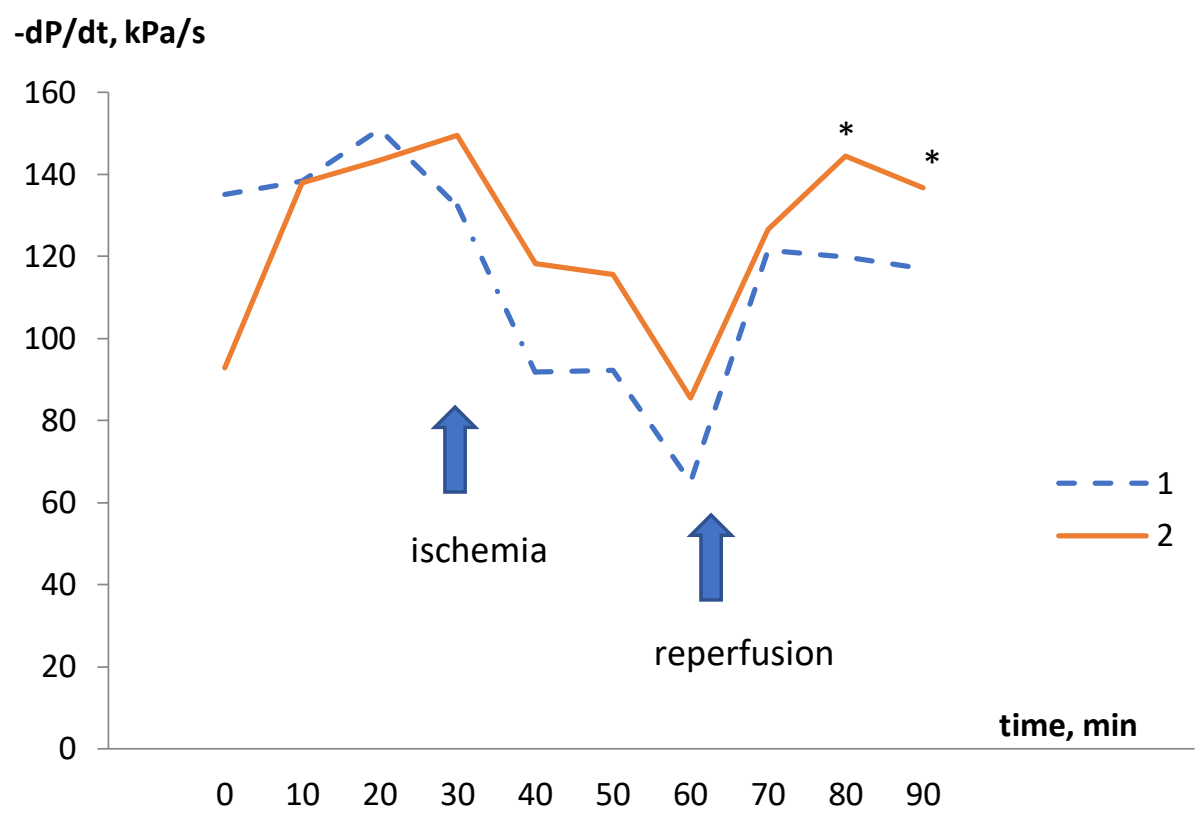

Figure 7. Effect of ATP-molsidomine combination on velocity of pressure decline in the left ventricle $(-\mathrm{dP} / \mathrm{dt}, \mathrm{kPa} / \mathrm{s})$ of isolated old rat hearts under conditions of adequate coronary perfusion, ischemia and reperfusion.

Notes: 1 - control - intact animals; 2 - experiment - ATP + molsidomine.

* $-\mathrm{P}<0.05$ - compared to control.

Thereby, the combined use of ATP and molsidomine in old rats has a positive effect on the power (Pmax) and speed $(+\mathrm{dP} / \mathrm{dt},-\mathrm{dP} / \mathrm{dt})$ indicators of myocardial contractile function under the influence of damaging factors - ischemia and reperfusion. With adequate coronary perfusion, the meanings of these parameters did not significantly differ for control and experimental animals.

The attention was drawn to the fact that during the combined use of ATP and molsidomine in old experimental rats, there was a significant increase of the maximally developed left ventricular isolated heart pressure (Pmax) only during the period of ischemia, and the rate indicators of myocardial contractility (+ $\mathrm{dP} / \mathrm{dt},-\mathrm{dP} / \mathrm{dt}$ ) were significantly higher in these animals during the reperfusion period. It should be noted that the overwhelming majority of researchers consider reperfusion to be not only a restorative, but also a damaging factor, therefore, it can be considered that when ATP and molsidomine are used together, they have a positive influence on the function of an isolated heart of old rats under the action of damaging factors - ischemia and reperfusion.

The positive effect of ATP and molsidomine in old rats was also identified in the study of the heart rhythm. In such a way, the heart rate of an isolated heart of old rats significantly decreased during ischemia for both control and experimental animals (Fig. 8). During reperfusion, the heart rate in the experimental rats was restored to the initial level and was significantly higher in comparison with the control ones. 


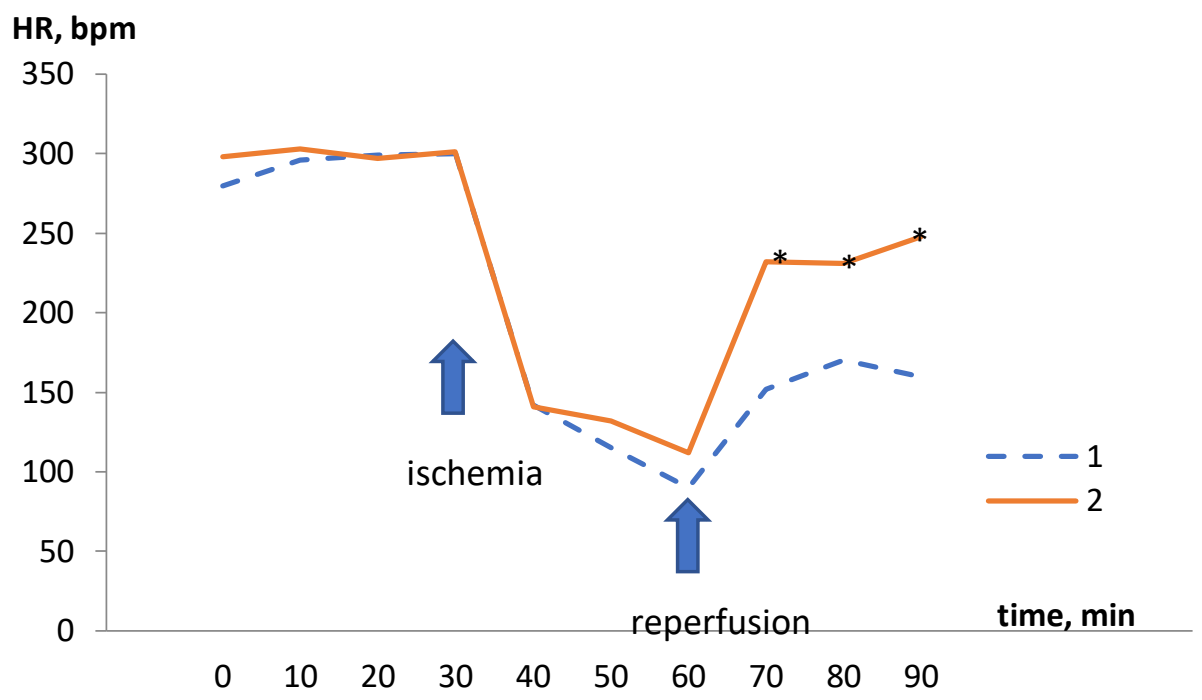

Figure 8. Effect of ATP-molsidomine combination on the heart rhythm (bpm) of isolated old rat hearts under conditions of adequate coronary perfusion, ischemia and reperfusion.

Notes: 1 - control- intact animals; 2 - experiment - ATP + molsidomine.

* - $\mathrm{P}<0.5$ - compared to control.

It should be noted that in the vast majority of intact old animals throughout the entire period of coronary perfusion, cardiac arrhythmias (arrhythmias, group extrasystoles) were observed, while during the use of ATP and molsidomine only in some cases single extrasystoles were observed. Perhaps, this effect is associated with the influence of ATP on the principal system of the heart, as it is known that ATP normalizes the excitation of the cells of the sinus and atrioventricular nodes and the principal system of the heart due to its influence on ion transport [9]. The known ability of ATP and adenosine to reduce the rate of transmission of excitation in the heart and, respectively, to increase the duration of the cardiac cycle phases [10]. This is especially important during the reperfusion, so far as during this period the greatest number of extrasystoles and paroxysmal arrhythmias is observed. In cardiological practice, ATP and adenosine are used in the treatment of paroxysmal supraventricular tachycardia and others heart rhythm disorders.

In addition, ATP, due to its vasodilatory effect, improves perfusion in the coronary artery system. In its turn, the hemodynamic effects of molsidomine include a decrease of systolic and end-diastolic pressure in the left ventricular, stroke volume, average arterial pressure and systemic vascular resistance, increased heart rate and diastolic coronary circulation [11, 12]. All this proves the expediency of the combined use of ATP and molsidomine in cardiological practice and is confirmed by the obtained data.

\section{Conclusions}

The combined use of ATP and molsidomine does not significantly affect the parameters of the contractile ability of the isolated heart of adult rats under different modes of perfusion but has a positive effect on the restoration of the heart rate after ischemia, during the period of reperfusion.

In old rats, the combined use of ATP and molsidomine has a marked positive influence on the contractile function of the isolated heart and heart rate, increases the inotropic reserve of the myocardium, increases tolerance and efficiency of the heart work under the action of damaging factors - ischemia and reperfusion.

All the above proves the expediency of the integrated use of ATP and molsidomine in the treatment of cardiovascular diseases. The additive effect of the components of the active ingredients of the studied combination will allow to reduce the doses of drugs that are used separately and reduce the potential risk of unwanted side effects. This is especially important for the elderly people, as the syndrome of polymorbidity and polypragmasia, which are observed in old age, it is advisable to prescribe combined drugs. 
Author Contributions: All authors participated equally in writing this commentary.

Conflicts of Interest: The authors declare no conflict of interest.

\section{Information about Authors:}

Vladislav V. Bezrukov - MD, DSc (Medicine), Prof., Full Member (Academician) of the NAMS of Ukraine, Director of the D. F. Chebotarev Institute of Gerontology NAMS of Ukraine, Head of the Department of Biology of Ageing and Experimental Life-Extension; https://orsid.org/0000-0002-3913-3818

Liana P. Kuprash - Dsc (Medicine), Head of the Geriatric Pharmacology Laboratory; https://orsid.org/0000-0001-8196$751 X$

Nina V. Sykalo - PhD (Biology), Leading Researcher of the Department of Biology of Ageing and Experimental LifeExtension; https://orsid.org/0000-0001-7812-8504

Tetyana M. Panteleymonova - PhD (Biology), Leading Researcher of the Geriatric Pharmacology Laboratory; https://orsid.org/0000-0002-3606-5805

Ludmila B. Sharabura - PhD (Biology), Leading Researcher of the Geriatric Pharmacology Laboratory; https://orsid.org/0000-0002-8182-7979

Vitaliy V. Olar - Junior Researcher of the Department of Biology of Ageing and Experimental Life-Extension; https://orsid.org/0000-0002-1298-2270 


\section{References}

1. Kosarev, V. V.; Babanov, S. A. Pharmacotherapy of ischemic heart disease: cytoprotectors in focus. Russian medical journal 2011, 19, 2, pp. 1-4. (in Russian)

2. Mikhin, V. P. Cytoprotection in cardiology: progress and prospects. Cardiology 2015, 10, pp. 22-28. https://doi.org/10.20514/2226-6704-2014-0-1-44-49 (in Russian)

3. Amosova, K. M.; Bereza, N. V. Influence of complex treatment with inclusion of ATP-long on indicators of contractile ability of a myocardium at patients with coronary heart disease at rest and at isometric loading. Galician Medical Bulletin 2001, 8, 4, pp. 10-12. (in Ukrainian)

4. Amosova, E. N.; Bereza, N. V.; Potapkova, I. V. The effect of complex therapy with the inclusion of ATP-long on the diastolic function of the left ventricle in patients with coronary heart disease at rest and with isometric exercise. Medicine 2002, 3-4, pp. 48-51. (in Russian)

5. Fukunaga, A. F.; Flacke, W. E.; Bloor, B. C. Hypotensive effects of adenosine triphosphate compared with sodium nitroprusside. Anesth. Analg. 1982, 61, 3, pp. 273-278.

6. Hoka, S.; Takeshita, A.; Aishima, K. et al. Vasodilator effects of adenosine triphosphate and sodium nitroprusside: comparisons during controlled hypotension. J. Anesth. 1987, 1, 2, pp. 143-147. https://doi.org/10.1007/s0054070010143

7. Chistik, T. Donators of nitric oxide in the treatment of cardiovascular pathology: nitrates or sydnoneimines? News of medicine and pharmacy 2014, 1-2, pp. 485-486. (in Russian) https://doi.org/10.22141/2224-1485.2.58.2018.131062.

8. Fallen, E. L.; Elliot, W. C.; Gorlin, R. Apparatus for study of ventricular function and metabolism in isolated perfused rat heart. J. Appl. Physiol. 1967, 22 (4), pp. 836-839.

9. Zhigunova, A. K. Cardioprotective drug ATP-long and its effect on metabolic processes in the myocardium. Ukr. Med. Bulletin 2012, 3, p 89. (in Russian)

10. Eltzschig, H. K. Adenosine: an old drug newly discovered. Anesthesiology 2009, 11, 4, pp. 904-915. https://doi.org/ 10.1097/ALN.0b013e3181b060f2

11. Vertkin, A. L.; Topolyansky, A. V. Molsidomin - new perspectives. Russian medical 2005, 7, pp. 430435. (in Russian) http://dx.doi.org/10.22141/2224-1485.2.58.2018.131062

12. Arkonas, B. M.; Kersten, J. R.; Wynsen, J. C. et al. Differential hemodynamic effects of the nitric oxide donor pirsidomine in comparison to SIN-1, nitroprusside, and nitroglycerin. Pharmacology 1996, 52, pp. $92-100$ https://doi.org/10.1159/000139372 